\title{
Empirical Analysis on the Impact of Internal Auditing on Firm Performance - A Case Study of Manufacturing Enterprises in Henan Province
}

\author{
Shang Wenna \\ Zhengzhou University of Industrial Technology, The Business School, 451151, Henan, China
}

Keywords: internal audit; enterprise performance; manufacturing enterprise; empirical research

\begin{abstract}
Discussing the manufacturing enterprises in Henan Province as the sample of research, the effect of internal audit on the performance of enterprises were analyzed by questionnaire. The results show that the quality and execution of internal auditors have a significant positive impact on the performance of the firm, and the internal audit independence is not relevant to the performance of the firm. The internal audit evaluation is divided into the internal audit independence, the quality of the employees, the technical conditions and the execution force.
\end{abstract}

\section{Introduction:}

Recently, many scholars have confirmed that the establishment of internal audit and the quality of corporate financial reports has a positive link, there are many scholars will raise the role of internal audit to the height of corporate governance. A large number of domestic and foreign researches also show that corporate governance and corporate performance there is a close positive correlation. In the internal audit and the performance of the company whether there is a relationship between, what kind of contact, how will the degree of contact, these are the focus of this paper. This paper discusses the difference between the internal audit independence, the quality of the internal audit staff, the technical conditions of the internal audit department and the execution power of the internal audit department through the comparison of the internal audit department of the internal audit department of the sample unit. The impact of non-financial aspects on firm performance. Which for Chinese enterprises to improve corporate performance have some practical significance.

\section{Literature Review and Research Hypothesis}

Relationship between internal audit and corporate performance at home and abroad is mainly from the perspective of normative research. From the point of view of fiduciary duty, the separation of ownership and management right makes the utility function of the principal and the agent different. Between the various stakeholders, an effective checks and balances are needed to ensure the interests of all factors. Internal audit appears as a supervisory evaluation mechanism. Internal audit is the control mechanism in the fiduciary responsibility system, ensuring that the organization is entrusted with financial responsibility and the effective performance of the trustee management responsibility. In order to successfully fulfill its fiduciary responsibility, the manager has promoted the status of internal audit to the position of corporate governance, so as to better serve the board and the manager. At present, the internal audit is causing the company more and more attention, status is also increasing, while the scope of internal audit is also expanding, including financial audit, business audit and social responsibility audit. People pay more and more attention to internal audit, continue to expand the internal audit to ensure the quality of corporate governance responsibilities, and ultimately achieve value added. Khan Taiyuan will be internal audit "value" is defined as: internal audit to improve the efficiency of corporate governance, then there is value-added internal audit effect. Therefore, the internal audit value of corporate governance at the corporate governance level is to improve the efficiency of corporate governance, thereby increasing 
the benefits of the parties involved in governance and achieving the objectives of corporate governance. In measuring the value of internal audit, you can through the internal audit of the various clients to assess the effectiveness of governance to carry out. This effect is multifaceted, both direct and indirect; both short-term and long-term effects; both include quantifiable financial indicators and non-quantifiable non-financial effects. The internal audit has the expertise and knowledge of the company's management expertise, so that it has the ability to increase the value of the organization. The value added of the internal audit for the company mainly comes from two aspects: on the one hand, through the implementation of regular audit activities, including financial audit, fraud audit, project budget and final accounts for the company to prevent mistakes, reduce costs play a role; Is to improve the operational environment and enhance the company's value creation by conducting unconventional audit activities with higher value-added content such as internal control training, advisory services, project evaluation, etc. From the perspective of the impact of internal audit on corporate performance, internal audit participation is also conducive to the improvement of corporate performance. To ensure the independence of internal audit, cannot do without the attention of leaders, Sirens and Belle's empirical study found that when the internal audit received strong support and active collaboration, its enthusiasm has been fully mobilized to help managers more effectively manage and Control the internal control system to develop, implement, help and promote the senior management to fulfill the fiduciary responsibility, improve the economic efficiency of the company, thus reflecting the internal audit of the company's activities, the rational use of resources, improve risk management and improvement, The constructive role. Goo Hui pointed out that the internal audit of the organizational status of high, to ensure that the audit results are given enough attention; wide range of responsibilities, will be able to penetrate into the enterprise, dig the truth, have more opportunities for enterprises to create value; The audit team also put forward higher requirements, adequate staff deployment is the scope of internal audit to expand the scope of the audit, the full potential of their potential, but also reflects the management of the internal audit of the investment situation, is the degree of emphasis on internal audit.

Above literature, found that most of the research focused on the internal audit for the company to bring value and value of the methods and ways, then people could determine the value of internal audit has been the role of the recognition of the academic community. However, only a small part of the paper referred to the relationship between internal audit and corporate performance, for this empirical research literature is more lacking. However, due to various objective and human factors, whether the internal audit can have an impact on corporate performance, which factors have an impact and how much impact, there is no sufficient data to prove. Therefore, this paper takes the manufacturing enterprises in Henan Province as a sample, and examines the current situation of the internal audit in the enterprise. At the same time, the relationship between the four factors of internal audit and the performance of the firm is studied through factor analysis, descriptive statistics and regression analysis.

On the basis of domestic and foreign research results, considering the relationship between internal audit evaluation, internal audit and corporate performance, the following research hypothesis is put forward and the empirical basis is given.

Assume that 1 (H1): The internal audit variable has multiple dimensions.

Assume that 2 (H2): Internal audit has a significant positive correlation with firm performance. Hypothesis 3 (H3): Internal audit has a direct positive impact on firm performance.

\section{Empirical Research Design}

Both the internal audit evaluation and the firm's performance are both Linker's five-point scale, where "1" represents very disagree, "2" represents less disagreement, "3" represents general agreement, "4" represents more agree, "5" stands for much agree. The four parts of internal audit evaluation are put forward: internal audit independence, internal audit staff quality, internal audit department technical condition and internal audit execution force. For each element, several questions are raised to measure each element. There are 18 items on the issue of internal audit 
evaluation. Mueller describes independence as a limitation of auditing that is not subject to significant audits and is not subject to significant limitations in the findings and conclusions of the audit or subsequent reports and states that in determining the scope of the internal audit, conducting audit work and communicating the results, Report the relationship to be free from any interference. This article will evaluate the independence of internal audit from four aspects: leadership attention, job independence, personnel reporting independence and departmental report independence. The evaluation of the quality of internal staff, from four aspects to consider: the proportion of the number of professional quality, follow-up study and job satisfaction. The evaluation of the technical conditions of the internal audit department is considered from three aspects: audit funding guarantee, audit information system application and information sharing degree. At present, there are not many researches on the internal audit execution ability. By summarizing the research results of the literature, the internal audit execution force is measured from the aspects of responsibility, function, eligibility, participation process, suggestions, number of suggestions and follow-up audit get on. The performance of the enterprise from the financial and non-financial aspects of the evaluation, including a total of 6 items. The measurement of financial indicators includes net assets yield, main business profitability and return on investment. Non-financial indicators include customer satisfaction, product / service quality and investment in new product development.

Samples mainly from the manufacturing enterprises in Henan Province. From January 2014 to June 2017 time to Henan Province, the manufacturing enterprises issued a total of 500 questionnaires, the recovery of valid questionnaires 218. Questionnaires are sent by e-mail, mail and field delivery. Chang Zhukov and Tan of the various enterprises to use the way to issue the questionnaire, the other by e-mail the way. The respondents surveyed were mainly internal auditors or internal auditors. After analyzing the valid questionnaires, descriptive statistical analysis, exploratory factor analysis and regression analysis were performed using SPSS statistical software.

The internal audit evaluation scale includes 18 measurement items that reflect the internal audit independence, internal audit execution, the quality of internal audit staff and the technical conditions of the internal audit department.

First, the results of the factorial analysis of the data of the internal audit evaluation showed that the KMO sample measurements of the internal audit sampling were 0.902. The Bartlett spherical test results show that the statistically significant probability of 0.000 is less than 0.01 , thus rejecting the zero hypothesis of the Bartlett spherical test. The above results show that the selected index data is very suitable for factor analysis. Two factors were extracted by principal component analysis and variance maximization orthogonal rotation method, including 18 items, factor 1 named internal audit execution force, factor 2 named internal audit independence, factor three named internal audit Personnel quality; factor four named the internal design department technical conditions. Which H04 because the load in the two factors are more than 0.5, it was deleted, and ultimately retained the 17 items. The load of the other factors in the respective factors is 0.5 or more, indicating that the convergence is very good, and the cumulative variance contribution of the four factors reaches $67.695 \%$, indicating that the measurement of the internal audit is Effective. The load factor, eigenvector score, cumulative proportion in a nova and factor naming of each retention factor are shown in Table 1, assuming that 1 is established.

Research variables measure the load factor

Factor One Factor Two Factor Three Factor Four

E01 internal audit department comments or suggestions are mostly received by senior management attention

E02 audit procedures / operations are in accordance with the corresponding audit charter operation

E03 internal audit more comprehensive responsibilities, including financial audit, business audit and management audit

E04 has a wider range of functions, including assessment functions and confirmation of advisory functions

The E05 Internal Audit Department will advise or advise senior management on the basis of the 
audit results

E06 internal audit to participate in post-evaluation and improvement, in the control, but also often involved in the relevant decision-making

E07 internal audit department in accordance with the audit charter to carry out a relatively complete follow - up audit
0.725
0.605
0.709
0.582
0.658
0.611

I01 senior management of the company's internal audit departments to pay great attention to the work

I02 internal audit department work / business relative independence is better, the operation has reasonable authority

I03 internal audit issued by the report independent and impartial

I04 The internal audit department is responsible and reported to the management and the audit committee at the same time

0.7450 .6920 .661

H01 internal audit staff professional ability and cross-professional knowledge to master better

H02 internal audit staff often participate in the corresponding professional follow-up training

H03 number of internal audit staff accounted for the proportion of total staff more reasonable 0.8030 .8010 .684

T01 internal audit department has its own very well-funded audit funding guarantee

T02 internal audit departments and other functional departments to share a higher degree

T03 company has a more comprehensive audit information system, and internal auditors can be skilled in the use of 0.7180 .6580 .623

Characteristic value 8.3391 .5691 .2781 .017

Cumulative variance contribution (\%) 20.68438 .36853 .94467 .797

In addition, the results of the factor analysis of the performance evaluation of the enterprise performance evaluation, the results show that the enterprise performance sampling appropriate KMO sample measurement value of 0.843 . The Bartlett spherical test results show that the statistically significant probability is 0.000 , less than 0.01 . Exploratory factor analysis results are extracted from the two factors: financial indicators and non-financial indicators, the cumulative factor of the cumulative variance of $73.078 \%$, indicating that the measurement of corporate performance is more effective.

Later in the internal audit work cannot just emphasize the technical input, but also pay attention to the improvement of the quality of personnel. And the implementation of the internal audit of the average is currently in a level on the side, which also shows that the implementation of enterprises have a certain concern. Correlation analysis can show the relationship between the factors and the direction of the close, regression analysis can further indicate the direction of the relationship between the factors that there is a causal relationship between the factors. This section analyzes the causal relationship between internal audit and corporate performance variables. The four factors of internal audit are used as explanatory variables, and the two factors of enterprise performance are analyzed as regression variables. The results are shown in Table 3. From the regression analysis results in Table 3, it can be found that the four factors of internal audit have the ability to interpret the financial indicators of 0.572, indicating that the four factors of internal audit have reached 57.2\% of the financial performance. And the internal audit execution, the quality of internal auditors and the technical conditions of the internal audit department have a significant positive impact on the financial indicators. Among them, the impact of internal audit execution on the financial indicators, indicating that the implementation of internal audit will have a significant impact on corporate financial performance. Secondly, the quality of the internal audit staff and the technical conditions of the internal audit department have a greater impact on the financial indicators , indicating that the quality of internal audit staff and departmental technology investment will be on the enterprise The financial performance of the more significant impact. 
The four factors of internal audit explain the non-financial indicators of 0.235 , indicating that the use of internal audit of the four factors of financial performance to explain the ability to reach 23.5\%. And the internal audit execution and the internal audit staff quality have a significant positive impact on the financial indicators. Among them, the quality of internal auditors has a greater impact on the financial indicators $(\beta=0.212 * *)$, followed by the internal audit department technical conditions also have a greater impact on the financial indicators $(\beta=0.218 *)$, indicating the quality of internal audit staff Sector technology investment will have a significant impact on the financial performance of enterprises.

Explain variables that are interpreted by variables

Financial indicators Non-financial indicators

Internal Audit Independence ( $\beta$ )

Internal Audit Execution $(\beta)$

Quality of Internal Auditors $(\beta)$

Internal audit department technical conditions $(\beta) 0.025$

\begin{tabular}{lcc}
0.225 & & 0.099 \\
$0.445 * * *$ & & $0.218 *$ \\
$0.223 * * *$ & & $0.212 * *$ \\
$0.180 * *$ & \multicolumn{2}{c}{0.044} \\
F value & 70.896 & 15.513 \\
P value. & 000 & .000 \\
$\mathrm{R}^{2}$ & .572. & 235
\end{tabular}

$* \mathrm{P}<0.05, * * \mathrm{P}<0.01, * * * \mathrm{P}<0.001$, multivariate regression analysis using mandatory variable entry method, $\mathrm{F}$ for the test equation significant $\mathrm{F}$ statistic, $\mathrm{P}$ value for the accompanying probability, R2 for the decision coefficient, Standard regression coefficient. Analysis of the data in third chart shows that the assumption that the independence of internal audit does not have a significant positive impact on financial performance and non-financial performance, perhaps because although the independence of the internal audit is very important, it is doing the internal The prerequisites for the audit work, but this does not mean that independence will have an intuitive impact on business performance. A company's internal audit of the independence of high, not necessarily the performance of the enterprise will be very good, corporate performance will be subject to some other factors within the impact of internal audit. In addition, the technical conditions of the internal audit department did not have a significant positive impact on non-financial performance, indicating that the high technical input to the internal audit sector is not necessarily conducive to the improvement of non-financial performance of enterprises, and only technology is not enough, The key is the quality of the application of technology personnel. Therefore, enterprises in the case of investment in technology, should pay more attention to the application of technology, improve the ability of internal auditors to apply technology.

\section{Conclusion}

In view of the above conclusions, enterprises in the future audit work should pay attention to: First, the independence of the internal audit is also an urgent need to strengthen, not only to ensure the independence of the internal audit department, but also to ensure the independence of internal audit staff, and in its Second, the quality of internal auditors have yet to be improved, each member needs a certain degree of expertise and ability, at the same time, enterprises should also focus on follow-up education; Third, the internal audit The technical requirements of the department or the enterprises need to give appropriate attention to the place, there is no good technology as a support, if the internal audit cannot be completed. 


\section{References}

[1] Sheng Taiyuan. Research on Value-added Internal Audit from the Perspective of Corporate Governance [J]. Finance Monthly (Theory), 2009.1.

[2]McFaul, L. Enhancing the value of Internal Audit: ten key questions [J] .Accountancy Ireland, June 2006, VOI.38, No.3: 34-37.

[3] Lou Changchun, Goo Hui. The influencing factors of internal audit characteristics and its effects research from the Chinese SME plate evidence [J]. Audit Research, 2008,2: 86-91.

[4] Sirens, G., and I. DE Beetled. Building a research model for internal auditing: insights from literature and theory specification cases [J]. International Journal of Accounting, Auditing and Performance Evaluation, 2006a, Vol.3, No .4: 452-470.

[5] Li Hominy. The independence of internal audit _ Based on the internal audit organization reporting relationship [J]. Audit Research, 2009,1. 